\title{
Melanocortin receptors as novel effectors of macrophage responses in inflammation
}

\author{
Hetal B. Patel *, Trinidad Montero-Melendez, Karin V. Greco and Mauro Perretti \\ William Harvey Research Institute, Barts and The London School of Medicine, Queen Mary University of London, London, UK
}

Edited by:

Amiram Ariel, University of Haifa, Israel

\section{Reviewed by:}

Paola Allavena, Clinical Institute

Humanitas, Italy

Anna Catania, Fondazione IRCCS Ca'

Granda Ospedale Maggiore Policlinico

di Milano, Italy

\section{${ }^{*}$ Correspondence:}

Hetal B. Patel, William Harvey

Research Institute, Barts and The

London School of Medicine, Queen

Mary University of London,

Charterhouse Square, London EC1M

6BO, UK

e-mail:h.b.patel@qmul.ac.uk
Macrophages have crucial functions in initiating the inflammatory reaction in a strict temporal and spatial manner to provide a "clear-up" response required for resolution. Hormonal peptides such as melanocortins modulate macrophage reactivity and attenuate inflammation ranging from skin inflammation to joint disease and reperfusion injury. The melanocortins (e.g., adrenocorticotrophin, $\mathrm{ACTH}$ and $\alpha \mathrm{MSH}$ ) elicit regulatory properties through activation of a family of GPCRs, the melanocortin (MC) receptors; $\mathrm{MC}_{1}-\mathrm{MC}_{5}$. Several studies have focused on $\mathrm{MC}_{1}$ and $\mathrm{MC}_{3}$ as anti-inflammatory receptors expressed on cells of the macrophage lineage. We review here elements of the melanocortin pathway with particular attention to macrophage function in anti-inflammatory and pro-resolving inflammatory settings. Evidence shows that $\mathrm{ACTH}, \alpha \mathrm{MSH}$, and other $\mathrm{MC}$ agonists can activate $\mathrm{MC}_{1}$ and $\mathrm{MC}_{3}$ on macrophage through $\mathrm{cAMP}$ and/or NFKB-dependent mechanisms to abrogate pro-inflammatory cytokines, chemokines, and $\mathrm{NO}$ and enhance anti-inflammatory mediators such as IL-10 and HO-1. Melanocortins and their receptors regulate inflammation by inhibiting leukocyte recruitment to and interaction with inflamed tissue. An intensely exciting addition to this field of research has been the ability of an aMSH analog; AP214 to activate $\mathrm{MC}_{3}$ expressed on macrophage to enhance their clearance of both zymosan particles and apoptotic neutrophils thus putting melanocortins in line with other pro-resolving mediators. The use of mouse colonies mutated or nullified for $\mathrm{MC}_{1}$ or $\mathrm{MC}_{3}$, respectively as well as availability of selective $\mathrm{MC}$ receptor agonist/antagonists have been key to deciphering mechanisms by which elements of the melanocortin system play a role in these phenomena. We review here melanocortin pathway components with attention to the macrophage, reiterating receptor targets required for pro-resolving properties. The overall outcome will be identification of selective MC agonists as a strategy for innovative anti-inflammatory therapeutics.

Keywords: inflammation, resolution, macrophage, melanocortins, melanocortin receptor, melanocyte stimulating hormone, G-protein coupled receptor, anti-inflammatory therapeutics

\section{INTRODUCTION}

An inflammatory reaction is characterized by cellular recruitment within a tissue that firstly involves an acute phase whereby neutrophils act as invaders to release toxins to kill and eliminate foreign encounters. Macrophages play a crucial role in the latter phase of this inflammatory reaction. At the site of injury their ultimate goal is counterbalance the acute phase to cease inflammation and clear-up detrimental artifacts including pathogens and debris as well as apoptotic cells from the environment. To disperse inflammation macrophage must complete complex reactions, including chemotaxis to move to the site of inflammation, phagocytose particles or apoptotic cells (process of efferocytosis) and secrete cytokines/chemokines, lipid mediators, reactive oxygen species, and other factors to underpin an immune response facilitating healing/repair and return to normal homeostatic physiology. Pathological conditions can arise as a consequence of disruption to the sequence of events leading to resolution of inflammation. There has been a recent spate in research to identify and understand these biochemical pathways and mediators enhancing the resolution of inflammation by macrophage in the hope to discover new therapeutics that "switch on" this protective arm of inflammation. Within the umbrella of anti-inflammatory and pro-resolution mediators being investigated are the omega-3 fatty acid derived resolvins, aspirin-related lipoxins, and the glucocorticoid induced protein Annexin Al. One other such pathway gaining attention within this field includes the melanocortin peptides and their counterpart melanocortin receptors.

\section{THE MELANOCORTIN SYSTEM}

Melanocortins are derived from proteolytic cleavage of proopiomelanocortin (POMC), a hormone first thought to be expressed only within the pituitary. Evidence now shows that POMC is also expressed within peripheral cells and tissues (Blalock, 1985). The enzymes proprotein convertase 1 (PC1) and 2 (PC2) belong to a conserved family of serine proteinases of the subtilisin/kexin-type that also include furin, PC4, PACE4, PC5/6, and PC7/LPC/PC8. Their action upon single and/or pairs of dibasic residues within the POMC sequence generate the melanocortin peptides; adrenocorticotrophin (ACTH), $\alpha-, \beta-, \gamma$-melanocyte stimulating hormone. PC1 leads to generation of full-length 
pro-ACTH ${ }_{1-39}$ and $\beta$-lipotropin. PC1 then further cleaves $\beta$ lipotropin to generate $\gamma$-lipotropin and $\beta$-endorphin, and proACTH to generate $N$-pro-opiocortin (POC), joining peptide (JP), and ACTH. The down-stream actions of PC2 result in production of $\mathrm{ACTH}_{1-17}$ and corticotrophin-like intermediate lobe peptide (from ACTH), $\gamma \mathrm{MSH}$ (from $N$-POC), and $\beta$-MSH (from $\beta$-lipotropin). Alpha-MSH ( $\alpha \mathrm{MSH})$ is generated by the combined actions of carboxypeptidase (CPE), peptidylglycine alphaamidating mono-oxygenase (PAM), and $N$-acetyltransferase $(N$ AT) on $\mathrm{ACTH}_{1-17}$ (Mountjoy, 2010; Figure 1).

The biological activity of the ACTH and MSH species occurs through activation of melanocortin receptors (MC) of which five have been cloned so far. All are seven transmembrane coupled to s-type G-proteins thus positively coupled to adenylate cyclase; their activation leading to increases in intracellular cAMP and, possibly partly independently from it, down-regulation of nuclear factor-kappa beta activation (Wikberg et al., 2000; Gantz and Fong, 2003). $\mathrm{MC}_{1}$ is the receptor expressed on melanocytes, responsible for $\mathrm{MSH}$ control over skin pigmentation, whereas $\mathrm{MC}_{2}$ is the canonical ACTH receptor, expressed on adrenal cells and responsible for glucocorticoid synthesis and release. The other MCs have less clear-cut biological functions. Within the central nervous system, $\mathrm{MC}_{4}$ is actively studied for its role in feed control, pain, and sexual health; $\mathrm{MC}_{5}$ might modulate exocrine gland activity (Gantz and Fong, 2003). $\mathrm{MC}_{3}$ might exert a control over energy metabolism (Butler et al., 2000), but our own work has indicated an important modulatory role for this receptor in the control of the host inflammatory response (Getting et al., 2002). Of interest here, there is now ample evidence that $\mathrm{MC}$, especially $\mathrm{MC}_{1}, \mathrm{MC}_{3}$, and $\mathrm{MC}_{5}$ are distributed on peripheral cells (Catania et al., 2010).

\section{PRODUCTION OF $\alpha$ MSH AND EXPRESSION OF MC RECEPTORS BY MACROPHAGE}

Melanocortins are expressed and functionally active on the macrophage. Star et al. (1995) reported increases in cAMP accumulation in RAW 264.7 macrophage (shown to express $M_{1}$ and $\mathrm{MC}_{3}$ but not $\mathrm{MC}_{5}$ ) upon $\alpha \mathrm{MSH}$ (pan agonist) incubation, suggestive of the presence of functionally active MCs on the cell surface (Star et al., 1995; Li and Taylor, 2008). Production of $\alpha \mathrm{MSH}$ by these cells was also noted with further augmentation of the response upon TNF $\alpha$ stimulation. These two lines of evidence along with the anti-inflammatory action of $\alpha \mathrm{MSH}$ to reduce nitric oxide release by RAW 264.7 macrophage suggest that $\alpha \mathrm{MSH}$ may act in an autocrine/paracrine manner by counteracting pro-inflammatory effect of cytokines (Star et al.,
1995). A similar autocrine circuit emerged in a latter study with human monocyte/macrophage THP-1 cells. Here, incubation of resting macrophage with an antibody recognizing $\mathrm{MC}_{1}$ on its own increased TNF $\alpha$ release, with the addition of $\alpha \mathrm{MSH}$ reducing this response. Furthermore the presence of the anti- $\mathrm{MC}_{1}$ attenuated this inhibitory signal caused by $\alpha \mathrm{MSH}$. Collectively, these data indicate that MC receptor agonists limit pro-inflammatory cytokine production from macrophages, possibly being pivotal also in peripheral autocrine circuits (Taherzadeh et al., 1999).

Expression of melanocortin receptors is not only restricted to macrophage cell lines, as $\mathrm{MC}$ receptor mRNA has been detected in primary rodent macrophage of alveolar $\left(\mathrm{MC}_{1}\right.$ and $\left.\mathrm{MC}_{3}\right)$, knee joint $\left(\mathrm{MC}_{3}\right)$, mesentery $\left(\mathrm{MC}_{1}\right.$ and $\left.\mathrm{MC}_{3}\right)$, and peritoneal $\left(\mathrm{MC}_{1}\right.$, $\mathrm{MC}_{3}$, and $\mathrm{MC}_{5}$ ) origin and human macrophage blood derived macrophage $\left(\mathrm{MC}_{1}, \mathrm{MC}_{3}\right.$, and $\mathrm{MC}_{5}$; Getting et al., 2002, 2003, 2008; Andersen et al., 2005; Leoni et al., 2008; Montero-Melendez et al., 2011).

\section{MELANOCORTINS RECEPTOR ACTIVATION ON MACROPHAGE AUGMENT ANTI-INFLAMMATORY RESPONSES}

In inflammatory/tissue injury settings, activation of MCs can influence a number of fundamental macrophage functions including:

(1) antagonizing the release of pro-inflammatory cytokines, chemokines, nitric oxide

(2) inhibiting leukocyte chemoattraction

(3) inducing release of anti-inflammatory cytokines and expression of heme oxygenase- 1

(4) augmenting phagocytosis and efferocytosis.

It should be noted that $\mathrm{MC}$ receptor activation can also affect macrophage responsiveness indirectly. For instance, the existence of a circuit involving $\mathrm{MC}_{3}$ and $\mathrm{MC}_{4}$ within the $\mathrm{CNS}$ that activates descending cholinergic fibers to activate anti-inflammatory nicotinic receptors have been described (Catania, 2007). Here we will restrict our overview on the direct effects of $\mathrm{MC}$ receptor on this cell type and discuss now some of the properties listed above in more detail.

\section{MELANOCORTINS INHIBIT CYTOKINE PRODUCTION}

The ability of melanocortin peptides to reduce macrophage release of pro-inflammatory mediators and increase anti-inflammatory mediators is a well-understood phenomenon with a number of

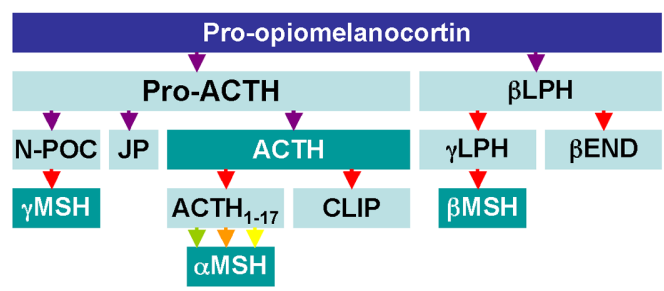

Prohormone convertase 1

$\checkmark$ Prohormone convertase 2

$\checkmark$ Carboxypeptidase

$\checkmark$ Peptidylglycine $\alpha$-amidating monooxygenase

$\mathrm{N}$-acetyltransferase

FIGURE 1 | Biochemical processing of the POMC gene product as detailed in the pituitary. The processing of POMC and products by posttranslational modification enzymes is depicted by arrows. Agonists of the melanocortin receptors MC1-MC5 are highlighted. 
groups contributing to this field. For example Capsoni et al. (2009) stimulated peripheral blood derived monocytes in vitro with monosodium urate crystals in the presence of $\alpha \mathrm{MSH}$ (pan agonist) or (CKPV) 2 (a biologically potent Lys-Pro-Val peptide linked by Cys-Cys residues) and found significant reductions in IL-1 $\beta$, IL-8, and TNF $\alpha$ release into supernatants (Capsoni et al., 2009). We treated the RAW264.7 mouse macrophage cell line with $\mathrm{ACTH}_{1-39}$ (pan agonist) and MTII, amore stable $\alpha \mathrm{MSH}$ derivative with higher affinity for $\mathrm{MC}_{3}$ and $\mathrm{MC}_{4}$ promoted an increase in cAMP accumulation and release of anti-inflammatory cytokine IL-10, the later effect being abrogated when cells were treated with $\mathrm{H}-89$ (protein kinase A [PKA] inhibitor) suggesting signaling down-stream of $\mathrm{MC}_{3}$ and not $\mathrm{MC}_{4}$ (as RAW264.7 did not express $\mathrm{MC}_{4}$ ) was through the cAMP-PKA pathway (Lam et al., 2006). In similar experiments both ACTH and MTII elicited in a CAMPPKA dependent manner cytoprotective and anti-inflammatory heme oxygenase-1 (HO-1) but not heme oxygenase-2, heat shock protein 70 and 90 in RAW267.4 cells (Lam et al., 2005). Mandrika et al. (2001) showed dual signaling mechanism by which $\alpha \mathrm{MSH}$ inhibited nitric oxide production by RAW267.4 macrophage. One pathway dependent of $\mathrm{MC}_{1} / \mathrm{cAMP}$ activation and the other causing inhibition of $\mathrm{NF} \kappa \mathrm{B}$ translocation in a cAMP-independent manner. Other specialized cells of the macrophage lineage such as microglia treated with $\alpha \mathrm{MSH}$ or ACTH substantially reduced $\mathrm{TNF} \alpha$, IL- 6 , and nitric oxide increases caused by LPS + IFN $\gamma$ activation, suggesting that $\mathrm{MC}$ peptides exert their anti-inflammatory actions on peripheral as well as central cells of the phagocytic lineage. There is evidence of active MC receptors because the same study reported that $\alpha \mathrm{MSH}$ could induce cAMP accumulation in both resting and activated microglia (Delgado et al., 1998).

Rat macrophage isolated from gouty knee joints also accumulated intracellular cAMP upon treatment with melanocortin peptide; ACTH (Getting et al., 2002). More recently functionality of MC receptors by cAMP readout on murine alveolar macrophage was confirmed after incubation with $\alpha \mathrm{MSH},\left[\mathrm{D}-\operatorname{Trp}^{8}\right] \gamma \mathrm{MSH}$ ( $\mathrm{MC}_{3} / \mathrm{MC}_{5}$ agonist), and MSO5 ( $\mathrm{MC}_{1}$ agonist; Getting et al., 2008; Joseph et al., 2010). Together these studies suggest that the cAMP pathway represents a common underlying mechanism for melanocortin to deliver anti-inflammatory effects. Manna and Aggarwal stimulated human monocytes with various inflammatory agents including TNF $\alpha$, LPS, ceramide, and okadaic acid to obtain NFKB activation, which was diminished in cells treated with $\alpha \mathrm{MSH}$ (Manna and Aggarwal, 1998). The agonistic effect appeared to be cAMP-dependent such that inhibitors of adenylate cyclase and PKA reversed the inhibitory effect of $\alpha \mathrm{MSH}$. Furthermore $\alpha \mathrm{MSH}$ inhibition of degradation of the NFKB inhibitory subunit I $\kappa \mathrm{B} \alpha$ and nuclear translocation of $\mathrm{p} 65$ subunit were also noted (Manna and Aggarwal, 1998).

Collectively these data appear to show that the antiinflammatory actions of $\alpha \mathrm{MSH}$ are dependent on $\mathrm{MC}_{1}, \mathrm{MC}_{3}$, and/or $\mathrm{MC}_{5}$ receptor activation and triggers inhibition of $\mathrm{NF} \kappa \mathrm{B}$ in a cAMP-dependent and independent manner through molecular links which are yet to be deciphered.

\section{MELANOCORTINS INHIBIT CHEMOTAXIS OF LEUKOCYTES}

As discussed so far, melanocortins are able to dampen macrophage release of pro-inflammatory mediators in inflammatory settings.
These phenomena were exploited further by Capsoni et al. (2009) who showed that melanocortins could influence the monocytes ability to recruit and prime neutrophils. Chemotaxis of neutrophils treated with $\alpha \mathrm{MSH}$ or $(\mathrm{CKPV})_{2}$ was examined using a boyden chamber assay and supernatants collected from monosodium urate crystal-stimulated monocytes as the source of chemoattractants. Chemotaxis was significantly reduced in neutrophils treated with agonist compared to controls. Furthermore reduced chemiluminescence (as a marker of reactive oxygen intermediates) production by pre-treated primed neutrophils was observed, in line with other studies showing melanocortin peptides can inhibit chemotaxis and generation of reactive oxygen species (Catania et al., 1996; Getting et al., 1999a; Capsoni et al., 2009).

To decipher what role $\mathrm{MC}_{3}$ has on leukocyte interaction with the inflamed mesentery, experiments were performed using pharmacological agents and mice nullified for $\mathrm{MC}_{3}$ where the superior mesenteric artery was occluded for $35 \mathrm{~min}$ followed by reopening to allow for blood reperfusion. Treatment with $\left[\mathrm{D}-\operatorname{Trp}^{8}\right] \gamma \mathrm{MSH}$, a $\mathrm{MC}_{3} / \mathrm{MC}_{5}$ agonist did not alter cell rolling but decreased cell adhesion and emigration compared to vehicle control an effect not observed in $M c 3 r-/-$ mice. These data were mirrored by augmented KC and MCP-1 responses in mesenteric tissues of Mc3r-/- mice suggesting $\mathrm{MC}_{3}$ is able to regulate leukocyte interaction with postcapillary venules and regulate levels of proinflammatory molecules in ischemia reperfusion injured tissues (Leoni et al., 2008). Moreover, whilst agonizing more than one $\mathrm{MC}$ receptor, the vasculoprotective properties of $\left[\mathrm{D}-\operatorname{Trp}^{8}\right] \gamma \mathrm{MSH}$ are solely transduced by $\mathrm{MC}_{3}$.

Of interest, the modulation of chemokines occurred in the tissue and not with respect to plasma levels, moreover, levels of the cytokines IL- $1 \beta$ and TNF $\alpha$ were not affected by pharmacological treatment with $\left[\mathrm{D}-\mathrm{Trp}^{8}\right] \gamma \mathrm{MSH}$ or absence of the $\mathrm{MC}_{3}$ gene. The "selective" effect on tissue chemokine levels may be secondary to inhibition of activation of resident cells, such as tissue macrophages and connective tissue type mast cells (Kubes and Granger, 1996; Tailor et al., 1999).

In similar experimental settings, the effects of a small molecule $\mathrm{MC}_{1}$ agonist, compound BMS-470539 (Kang et al., 2006) inhibited cell adhesion, and emigration, an effect that was lacking in yellow ${ }^{\mathrm{e} / \mathrm{e}}$ mice. Interestingly, unlike $M c 3 r-/-$ mice, the yellow ${ }^{\mathrm{e} / \mathrm{e}}$ mice (expressing non-functional $\mathrm{MC}_{1}$ ) displayed a comparable leukocyte adhesion and emigration response to wild types. Collectively these two studies identify a complex scenario whereby although both $\mathrm{MC}_{1}$ and $\mathrm{MC}_{3}$ are expressed in the inflamed mesentery, $\mathrm{MC}_{1}$ may not be endogenously activated in ischemia reperfusion injury whereas $\mathrm{MC}_{3}$ is both exogenously and endogenously activated in this setting (Leoni et al., 2010). Future studies addressing the hypothetical generation of selective agonists post-ischemia reperfusion might help deciphering this apparent discrepancy.

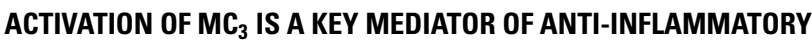 EFFECTS IN MACROPHAGES}

Until a decade ago, the mainstream school of thought was that the anti-inflammatory actions of melanocortin agonists were solely through $\mathrm{MC}_{1}$ activation (Lipton and Catania, 1997; Luger et al., 2003). We used two mouse colonies, one bearing a non-functional 
$\mathrm{MC}_{1}$ (yellow $^{\mathrm{e} / \mathrm{e}}$ mice) and the other knocked out for $\mathrm{MC}_{3}$ ( $M c 3 r-/-$ mice), to conclude that $\mathrm{MC}_{3}$ can be engaged by agonists with anti-inflammatory properties. Cultured primary peritoneal macrophage from yellow ${ }^{\mathrm{e} / \mathrm{e}}$ mice were treated with $\left[\mathrm{D}-\mathrm{Trp}^{8}\right] \gamma \mathrm{MSH}$ displaying a dose-dependent increase in cAMP accumulation, an effect reversed in the presence of an antibody to $\mathrm{MC}_{3}$. The release of the chemokine $\mathrm{KC}$ was abrogated in the presence of $\left[\mathrm{D}-\operatorname{Trp}^{8}\right] \gamma \mathrm{MSH}$ with the antagonist agouti related protein (AGRP) abolishing the inhibitory effect.

In another study mice pre-treated with ACTH were injected with MSU crystals to induce peritonitis. A reduced accumulation of PMN was observed in the peritoneal cavity of mice treated with ACTH compared to vehicle control, data that was mirrored by decreased levels of $\mathrm{KC}$ also within the cavity. Interestingly co-administration of SHU9119 (an $\mathrm{MC}_{3} / \mathrm{MC}_{4}$ antagonist) with ACTH inhibited the agonists effects suggesting ACTH was acting through $\mathrm{MC}_{3}$ and further confirmed by the detection of $\mathrm{MC}_{3}$ but not $\mathrm{MC}_{4}$ at the mRNA transcript level on peritoneal macrophage (Getting et al., 1999b). At a latter date, Getting et al. (2003) in the same peritonitis model using more selective $\mathrm{MC}_{3}$ agonists and yellow ${ }^{\mathrm{e} / \mathrm{e}}$ mice confirmed that indeed agonism at $\mathrm{MC}_{3}$ inhibited pro-inflammatory cytokines (IL-1) and chemokines (KC) and accumulation of neutrophils in the inflamed peritoneal cavity (Getting et al., 2003). Collectively these data suggest $\mathrm{MC}_{3}$ more than $\mathrm{MC}_{1}$ (at least in mouse) to be pivotal in bringing about the anti-inflammatory effects observed following treatment with these agonists (Getting et al., 1999b, 2003, 2006).

\section{$M_{3}$ REGULATES MACROPHAGE DIFFERENTIATION TO OSTEOCLASTS DURING INFLAMMATORY ARTHRITIS}

More recently $\mathrm{MC}_{3}$ has been implicated in the regulation of macrophage precursor differentiation to osteoclasts. Inflammatory arthritis was induced by injection of an arthritogenic serum into wild type and $M c 3 r-/-$, observing a higher prevalence and severity of disease observed in the latter genotype (Patel et al., 2010a). In a series of real time PCR analyses of extracts from the mouse ankle joint, a discrete set of inflammatory genes (13 out of 96) were upregulated in $M c 3 r-/-$ including IL-1 $\beta$, IL-6, NOS2, CCR4, CXCR3, CCL2 as compared to wild types. It is worthy to note here that major macrophage secretory products include IL-1 $\beta$ and IL-6 (Gordon, 2003).

Upon microscopic analyses of the ankle joints, a significantly higher number of joints were affected by bone erosion, as indicated by histological scores and number of TRAP-positive osteoclasts within the $M c 3 r-/-$ joint. This observation was corroborated by the higher levels of RANKL (a key driver of osteoclast formation) mRNA in Mc3r-/- ankle joints (Lacey et al., 1998). Although the exact mechanism was not characterized, some conclusion could be reached by the study of osteoclast formation in vitro. Bone marrow-derived macrophage from wild type and $\mathrm{Mc} 3 \mathrm{r}-\mathrm{I}-$ mice were differentiated to osteoclasts in the presence of M-CSF and RANKL. A defect was noted such that a higher number of osteoclasts were generated from macrophage absent of the $\mathrm{MC}_{3}$ gene compared to $\mathrm{MC}_{3}$ sufficient cells. The $M c 3 r-/-$ osteoclasts displayed an increased "eating" ability such that when cultured on calcium phosphate coated wells significantly more resorption pits could be observed and quantified. Interestingly $M c 3 r-/-$ cells had increased and sustained RANKL-mediated NFкB signaling compared to wild types; this finding could provide mechanistic support to the increased CCL2 synthesis observed by these cells (Patel et al., 2010a). Together with the study by Cornish et al. (2003), our work implicates a role for melanocortins and their melanocortin receptors in the regulation of macrophage differentiation to specialized cells, example being here the osteoclast. It is plausible that MCs may modulate macrophage differentiation in other specialized cells such as the microglia or Kupffer cells, with further implications for their therapeutic potential.

\section{MC $_{3}$ ACTIVATION ENHANCES RESOLUTION OF INFLAMMATION}

Resolution of inflammation is an important process required to reset tissue/cells to a state of normalization after insult/injury. During this process a number of endogenous pathways are activated in order to regain homeostatic balance after inflammation. An exciting enhancement to the field of melanocortin biology in inflammation has been the recent finding that AP214, a modified $\alpha \mathrm{MSH}$ analog, possesses prophagocytic and pro-resolving effects (Montero-Melendez et al., 2011), in line with the profile reported for resolvins and lipoxins (Schwab et al., 2007).

AP214 inhibits neutrophil recruitment in the zymosan peritonitis model, an effect that could be due, at least in part, to a modulation of macrophage phagocytic abilities of the particles. In vitro, AP214-treated biogel-elicited macrophages were incubated with zymosan particles to determine the percentage of phagocytic cells and number of ingested particles, observing an increment in both parameters. Such an effect of AP214 was also observed with respect to efferocytosis since this MSH analog augmented phagocytosis of human apoptotic neutrophils by mouse macrophages, an effect that was absent when $M c 3 r-/-$ macrophages were used. In in vivo settings, injection of apoptotic neutrophils into murine peritoneal cavities pre-treated with AP214 led to an increase in macrophage ingestion of neutrophils compared to vehicle control. This recent study has uncovered a new angle in which melanocortins and their receptors can affect the inflammatory reaction providing strong evidence for genuine pro-resolving activities centered on tight regulation of macrophage functions.

\section{CONCLUSION}

In this review we have highlighted the importance of melanocortins and their receptors in modulating the macrophage function in inflammation and tissue injury (see Figure 2). We have seen that $\mathrm{MC}$ activation does not merely reduce production of pro-inflammatory mediators, but can regulate cell differentiation as well as chemotaxis of leukocytes. Excitingly, melanocortins can now be added to the plethora of pro-resolution mediators by way of their ability to augment phagocytosis and efferocytosis; we predict these portfolio of properties will define other functions/biological properties of melanocortins in other aspects of resolution of inflammation in the years to come.

What does this mean for the development of melanocortinbased therapies? Noteworthy, ACTH has been used as early as the 1940s for the treatment of gouty and rheumatoid arthritis, yet as discussed above never were the mechanisms of actions deciphered until the recent decade (Hench et al., 1949; Gutman and Yu, 1950). What does remain in its infancy is the pattern in which MCs may 


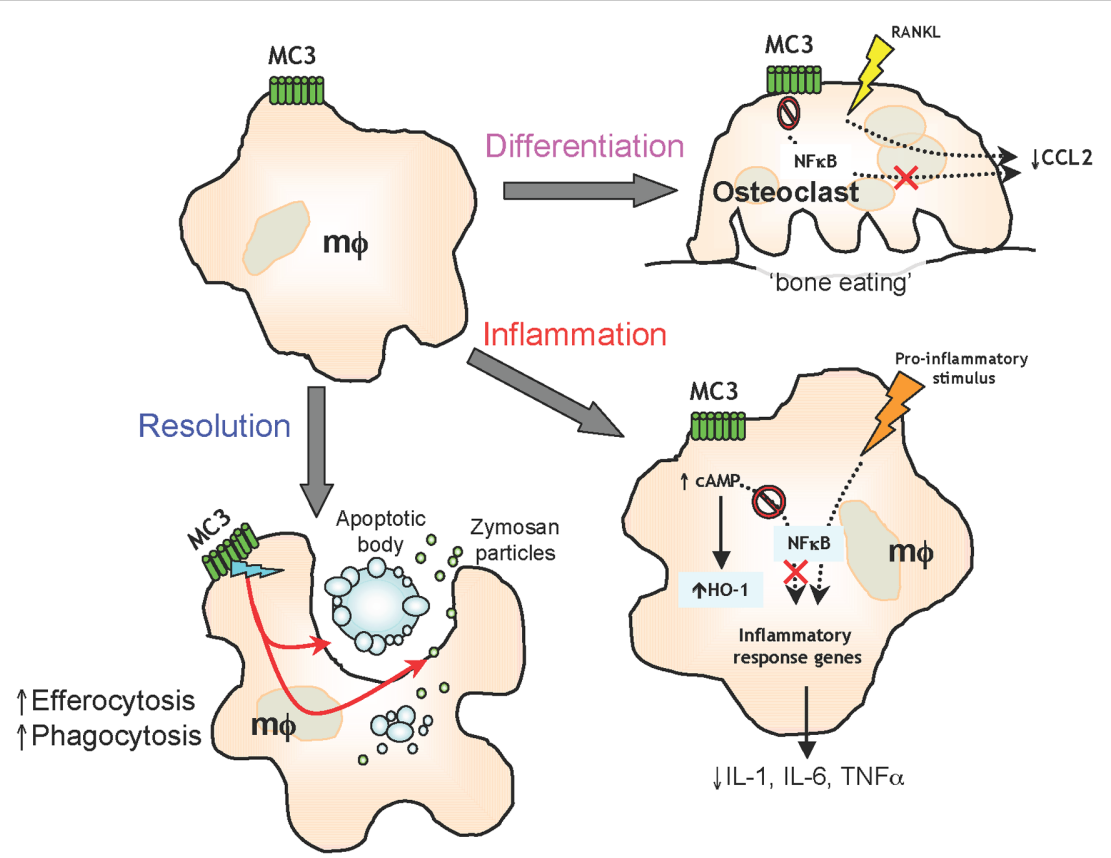

FIGURE 2 | Melanocortin receptor type 3 activation on macrophage $(m \phi)$ functions Activation of $\mathrm{MC}_{3}$ by endogenous or selective synthetic agonists leads to regulation of osteoclast generation, control of pro-inflammatory and anti-inflammatory mediators and resolution of inflammation by efferocytosis and phagocytosis.

be expressed in specific disease, nevertheless this area of research and drug development has become particularly eye-catching as seen with the development of AP214 for the treatment of postsurgical kidney injury following cardiac heart surgery in phase II trials (www.clinicaltrials.gov). Other melanocortin-based therapies are in the development pipeline for biotechnology companies with emphasis on obesity and sexual dysfunction as disease targets (Patel et al., 2010b).

We envisage over the next decade new drugs based on the melanocortin peptides - specifically targeting $\mathrm{MC}_{3}$ - to be developed and designed for the treatment of inflammatory conditions.

\section{REFERENCES}

Andersen, G. N., Hagglund, M., Nagaeva, O., Frangsmyr, L., Petrovska, R., Mincheva-Nilsson, L., and Wikberg, J. E. (2005). Quantitative measurement of the levels of melanocortin receptor subtype 1,2 , 3 and 5 and pro-opio-melanocortin peptide gene expression in subsets of human peripheral blood leucocytes. Scand. J. Immunol. 61, 279-284.

Blalock, J. E. (1985). Proopiomelanocortin-derived peptides in the immune system. Clin. Endocrinol. (Oxf.) 22, 823-827.

Butler, A. A., Kesterson, R. A., Khong, K., Cullen, M. J., Pelleymounter, M. A., Dekoning, J., Baetscher, M., and Cone, R. D. (2000). A unique metabolic syndrome causes obesity in the melanocortin-3 receptor-deficient mouse. Endocrinology 141, 3518-3521.

Capsoni, F., Ongari, A. M., Reali, E., and Catania, A. (2009). Melanocortin peptides inhibit urate crystalinduced activation of phagocytic cells. Arthritis Res. Ther. 11, R151.

Catania, A. (2007). The melanocortin system in leukocyte biology. $J$. Leukoc. Biol. 81, 383-392.

Catania, A., Lonati, C., Sordi, A., Carlin, A., Leonardi, P., and Gatti, S. (2010). The melanocortin system in control of inflammation. ScientificWorldJournal 10, 1840-1853.

Catania, A., Rajora, N., Capsoni, F., Minonzio, F., Star, R. A., and Lipton, J. M. (1996). The neuropeptide alpha-MSH has specific receptors on neutrophils and reduces chemotaxis in vitro. Peptides 17, 675-679.

These drugs would be better tolerated with a lower burden of sideeffects as they would mimic the body's way of naturally abating inflammation to promote pro-resolving and anti-inflammatory mediators.

\section{ACKNOWLEDGMENTS}

Work on melanocortin peptides and their receptors produced in the laboratory of the Authors has been funded, over the years, by several grants from the Arthritis Research UK (active project number 18049) and by one collaborative project between the William Harvey Research Foundation and Action Pharma A/S.

Cornish, J., Callon, K. E., Mountjoy, K. G., Bava, U., Lin, J. M., Myers, D. E., Naot, D., and Reid, I. R. (2003). alpha -Melanocyte-stimulating hormone is a novel regulator of bone. Am. J. Physiol. Endocrinol. Metab. 284, E1181-E1190.

Delgado, R., Carlin, A., Airaghi, L., Demitri, M. T., Meda, L., Galimberti, D., Baron, P., Lipton, J. M., and Catania, A. (1998). Melanocortin peptides inhibit production of proinflammatory cytokines and nitric oxide by activated microglia. J. Leukoc. Biol. 63, 740-745.

Gantz, I., and Fong, T. M. (2003). The melanocortin system. Am. J. Physiol. Endocrinol. Metab. 284, E468-E474.

Getting, S. J., Christian, H. C., Flower, R. J., and Perretti, M. (2002). Activation of melanocortin type 3 receptor as a molecular mechanism for adrenocorticotropic hormone efficacy in gouty arthritis. Arthritis Rheum. 46, 2765-2775.

Getting, S. J., Christian, H. C., Lam, C. W., Gavins, F. N., Flower, R. J., Schioth, H. B., and Perretti, M. (2003). Redundancy of a functional melanocortin 1 receptor in the anti-inflammatory actions of melanocortin peptides: studies in the recessive yellow (e/e) mouse suggest an important role for melanocortin 3 receptor. J. Immunol. 170, 3323-3330.

Getting, S. J., Flower, R. J., and Perretti, M. (1999a). Agonism at melanocortin receptor type 3 on macrophages inhibits neutrophil influx. Inflamm. Res. 48(Suppl. 2), S140-S141. 
Getting, S. J., Gibbs, L., Clark, A. J., Flower, R. J., and Perretti, M. (1999b). POMC gene-derived peptides activate melanocortin type 3 receptor on murine macrophages, suppress cytokine release, and inhibit neutrophil migration in acute experimental inflammation. $J$. Immunol. 162, 7446-7453.

Getting, S. J., Lam, C. W., Leoni, G., Gavins, F. N., Grieco, P., and Perretti, M. (2006). [D-Trp8]-gammamelanocyte-stimulating hormone exhibits anti-inflammatory efficacy in mice bearing a nonfunctional MC1R (recessive yellow e/e mouse). Mol. Pharmacol. 70, 1850-1855.

Getting, S. J., Riffo-Vasquez, Y., Pitchford, S., Kaneva, M., Grieco, P., Page, C. P., Perretti, M., and Spina, D. (2008). A role for MC3R in modulating lung inflammation. Pulm. Pharmacol. Ther. 21, 866-873.

Gordon, S. (2003). Alternative activation of macrophages. Nat. Rev. Immunol. 3, 23-35.

Gutman, A. B., and Yu, T. F. (1950). Effects of adrenocorticotropic hormone (ACTH) in gout. Am. J. Med. 9, 24-30.

Hench, P. S., Kendall, E. C., Slocumb, C. H., and Polley, H. F. (1949). The effect of a hormone of the adrenal cortex (17-hydroxy-11dehydrocorticosterone; compound E) and of pituitary adrenocorticotropic hormone on rheumatoid arthritis. Mayo Clin. Proc. 24, 181-197.

Joseph, C. G., Yao, H., Scott, J. W., Sorensen, N. B., Marnane, R. N., Mountjoy, K. G., and Haskell-Luevano, C. (2010). gamma-Melanocyte stimulation hormone (gamma-MSH) truncation studies results in the cautionary note that gamma-MSH is not selective for the mouse MC3R over the mouse MC5R. Peptides 31, 2304-2313.

Kang, L., McIntyre, K. W., Gillooly, K. M., Yang, Y., Haycock, J., Roberts, S., Khanna, A., Herpin, T. F., Yu, G., Wu, X., Morton, G. C., Tuerdi, H., Koplowitz, B., Walker, S. G., Wardwell-Swanson, J., Macor, J. E., Lawrence, R. M., and Carlson, K. E. (2006).
A selective small molecule agonist of the melanocortin-1 receptor inhibits lipopolysaccharide-induced cytokine accumulation and leukocyte infiltration in mice. J. Leukoc. Biol. 80, 897-904.

Kubes, P., and Granger, D. N. (1996). Leukocyte-endothelial cell interactions evoked by mast cells. Cardiovasc. Res. 32, 699-708.

Lacey, D. L., Timms, E., Tan, H. L., Kelley, M. J., Dunstan, C. R., Burgess, T., Elliott, R., Colombero, A., Elliott, G., Scully, S., Hsu, H., Sullivan, J., Hawkins, N., Davy, E., Capparelli, C., Eli, A., Qian, Y. X., Kaufman, S., Sarosi, I., Shalhoub, V., Senaldi, G., Guo, J., Delaney, J., and Boyle, W. J. (1998). Osteoprotegerin ligand is a cytokine that regulates osteoclast differentiation and activation. Cell 93, 165-176.

Lam, C. W., Getting, S. J., and Perretti, M. (2005). In vitro and in vivo induction of heme oxygenase 1 in mouse macrophages following melanocortin receptor activation. J. Immunol. 174, 2297-304.

Lam, C. W., Perretti, M., and Getting, S. J. (2006). Melanocortin receptor signaling in RAW264.7 macrophage cell line. Peptides 27, 404-412.

Leoni, G., Patel, H. B., Sampaio, A. L., Gavins, F. N., Murray, J. F., Grieco, P., Getting, S. J., and Perretti, M. (2008). Inflamed phenotype of the mesenteric microcirculation of melanocortin type 3 receptor-null mice after ischemia-reperfusion. FASEB J. 22, 4228-4238.

Leoni, G., Voisin, M. B., Carlson, K., Getting, S., Nourshargh, S., and Perretti, M. (2010). The melanocortin $\mathrm{MC}(1)$ receptor agonist BMS470539 inhibits leucocyte trafficking in the inflamed vasculature. $B r . J$. Pharmacol. 160, 171-180.

Li, D., and Taylor, A. W. (2008). Diminishment of alpha-MSH anti-inflammatory activity in $\mathrm{MClr}$ siRNA-transfected RAW264.7 macrophages. J. Leukoc. Biol. 84, 191-198.

Lipton, J. M., and Catania, A. (1997). Anti-inflammatory actions of the neuroimmunomodulator alpha-MSH. Immunol. Today 18, 140-145.
Luger, T. A., Scholzen, T. E., Brzoska, T., and Bohm, M. (2003). New insights into the functions of alpha-MSH and related peptides in the immune system. Ann. N. Y. Acad. Sci. 994, 133-140.

Mandrika, I., Muceniece, R., and Wikberg, J. E. (2001). Effects of melanocortin peptides in lipopolysaccharide/interferongamma-induced NF-kappaB DNA binding and nitric oxide production in macrophage-like RAW 264.7 cells: evidence for dual mechanisms of action. Biochem. Pharmacol. 61, 613-621.

Manna, S. K., and Aggarwal, B. B. (1998). Alpha-melanocytestimulating hormone inhibits the nuclear transcription factor NF-kappa B activation induced by various inflammatory agents. $J$. Immunol. 161, 2873-2880.

Montero-Melendez, T., Patel, H. B., Seed, M., Nielsen, S., Jonassen, T. E. N., and Perretti, M. (2011). The melanocortin agonist AP214 exerts anti-inflammatory and pro-resolving properties: evidence for a major involvement of the melanocortin receptor type 3 . Am. J. Pathol. 179, 259-269.

Mountjoy, K. G. (2010). Functions for pro-opiomelanocortin-derived peptides in obesity and diabetes. Biochem. J. 428, 305-324.

Patel, H. B., Bombardieri, M., Sampaio, A. L., D'Acquisto, F., Gray, M., Grieco, P., Getting, S. J., Pitzalis, C., and Perretti, M. (2010a). Anti-inflammatory and antiosteoclastogenesis properties of endogenous melanocortin receptor type 3 in experimental arthritis. FASEB $J$. 24, 4835-4843.

Patel, H. B., Leoni, G., Melendez, T. M., Sampaio, A. L., and Perretti, M. (2010b). Melanocortin control of cell trafficking in vascular inflammation. Adv. Exp. Med. Biol. 681, 88-106.

Schwab, J. M., Chiang, N., Arita, M., and Serhan, C. N. (2007). Resolvin E1 and protectin D1 activate inflammation-resolution programmes. Nature 447, 869-874.

Star, R. A., Rajora, N., Huang, J., Stock, R. C., Catania, A., and
Lipton, J. M. (1995). Evidence of autocrine modulation of macrophage nitric oxide synthase by alpha-melanocyte-stimulating hormone. Proc. Natl. Acad. Sci. U.S.A. 92, 8016-8020.

Taherzadeh, S., Sharma, S., Chhajlani, V., Gantz, I., Rajora, N., Demitri, M. T., Kelly, L., Zhao, H., Ichiyama, T., Catania, A., and Lipton, J. M. (1999). alpha-MSH and its receptors in regulation of tumor necrosis factoralpha production by human monocyte/macrophages. Am. J. Physiol. 276(Pt 2), R1289-R1294.

Tailor, A., Tomlinson, A., Salas, A., Panes, J., Granger, D. N., Flower, R. J., and Perretti, M. (1999). Dexamethasone inhibition of leucocyte adhesion to rat mesenteric postcapillary venules: role of intercellular adhesion molecule 1 and KC. Gut 45, 705-712.

Wikberg, J. E., Muceniece, R., Mandrika, I., Prusis, P., Lindblom, J., Post, C., and Skottner, A. (2000). New aspects on the melanocortins and their receptors. Pharmacol. Res. 42, 393-420.

Conflict of Interest Statement: The authors declare that the research was conducted in the absence of any commercial or financial relationships that could be construed as a potential conflict of interest.

Received: 30 June 2011; accepted: 22 August 2011; published online: 13 September 2011

Citation: Patel HB, Montero-Melendez T, Greco KV and Perretti M (2011) Melanocortin receptors as novel effectors of macrophage responses in inflammation. Front. Immun. 2:41. doi: 10.3389/fimmu.2011.00041

This article was submitted to Frontiers in Inflammation, a specialty of Frontiers in Immunology.

Copyright (c) 2011 Patel, MonteroMelendez, Greco and Perretti. This is an open-access article subject to a nonexclusive license between the authors and Frontiers Media SA, which permits use, distribution and reproduction in other forums, provided the original authors and source are credited and other Frontiers conditions are complied with. 